\title{
Novel SLC9A6 Variation in Female Carriers With Intellectual Disability and Atypical Parkinsonism
}

\author{
Haitian Nan, MD, Yeon-Jeong Kim, PhD, Mai Tsuchiya, MD, Aki Ishida, MD, Hirotaka Haro, MD, PhD, \\ Masaki Hiraide, MD, Toshihisa Ohtsuka, MD, PhD, and Yoshihisa Takiyama, MD, PhD
}

Neurol Genet 2022;8:e651. doi:10.1212/NXG.0000000000000651

\section{Abstract}

\section{Background and Objectives}

Variations in SLC9A6 cause the X-linked neurologic disorder Christianson syndrome in males. Meanwhile, female carriers with SLC9A6 variations may remain asymptomatic or develop intellectual disability, behavioral problems, and psychiatric illnesses. Only a few female carriers have been reported to have associated atypical parkinsonism in late life.

\section{Methods}

We present a Japanese family with a novel SLC9A6 variation identified by quad whole-exome sequencing analysis and a reverse phenotyping strategy. The molecular and cellular impacts of the W89R variation in vitro were examined.

\section{Results}

The missense variation (c.265T>C, p.Trp89Arg) in SLC9A6 cosegregated with atypical parkinsonism and intellectual disability in female carriers of this family. The female carriers in this family presented with bradykinesia, rigidity, and tremor, predominately on the right side. We found that the W89R variation changed membrane traffic of NHE6-harboring vesicles, indicating potential involvement in the disease pathogenesis.

\section{Discussion}

This study might have revealed an example of a monogenic origin of atypical parkinsonism in females with SLC9A6 variations and draw attention to this understudied female-specific phenotype in clinical practice.

\author{
Correspondence \\ Dr. Takiyama \\ ytakiyama@yamanashi.ac.jp
}

\section{MORE ONLINE}

$\checkmark$ Video

From the Department of Neurology (H.N., M.T., Y.T.), University of Yamanashi; Department of Biochemistry (Y.-J.K., T.O.), Graduate School of Medical Sciences, University of Yamanashi; Department of Rehabilitation (A.I.), Yamanashi University Hospital; Department of Orthopaedic Surgery (H.H.), University of Yamanashi; and Department of Neurology (M.H.), Kyonan Hospital, Yamanashi, Japan.

Go to Neurology.org/NG for full disclosures. Funding information is provided at the end of the article.

The Article Processing Charge was funded by the authors.

This is an open access article distributed under the terms of the Creative Commons Attribution-NonCommercial-NoDerivatives License 4.0 (CC BY-NC-ND), which permits downloading and sharing the work provided it is properly cited. The work cannot be changed in any way or used commercially without permission from the journal. 


\section{Glossary}

CS $=$ Christianson syndrome; MIBG $={ }^{123}$ I-metaiodobenzylguanidine; NHE $=\mathrm{Na}+\mathrm{H}+$ exchanger; SPECT $=$ single-photon emission CT; WES = whole-exome sequencing; WT = wild type.

The SLC9A6 gene encodes endosomal $\mathrm{Na}+\mathrm{H}+$ exchanger (NHE) protein NHE6. Variations in SLC9A6 cause the $\mathrm{X}$-linked neurologic disorder Christianson syndrome (CS) in males. ${ }^{1,2}$ Female carriers with SLC9A6 variations may remain asymptomatic or develop intellectual disability, behavioral problems, and psychiatric illnesses. ${ }^{3,4}$ Herein, we present a family with 3 carrier females carrying a c.265T $>$ C, p.Trp89Arg variation in SLC9A6. Our functional study suggests a potential impairment of endosomal trafficking by the W89R variation.

\section{Methods}

See Supplementary Material for details (links.lww.com/NXG/ A506).

\section{Standard Protocol Approvals, Registrations, and Patient Consents}

The study was approved by the Institutional Review Board of the University of Yamanashi. Written informed consent was obtained from all participants.

\section{Data Availability}

Data are available from the corresponding author on reasonable request.

\section{Clinical Findings}

The proband is a 51-year-old right-handed woman. She had learning problems at elementary school, and after graduating, she did some simple manual work in a factory. At age 48 years, she began having difficulty with fine motor skills in her right hand and her gait became slower. On examination, she exhibited bradykinesia, rigidity, and exaggerated deep tendon reflexes in the limbs, predominately on the right side. She exhibited conjugate, bilateral limitation of upgaze and downgaze eye movements (Video 1). She showed postural tremor in the hands and the glabellar tap sign. There was no limb dystonia, myoclonus, apraxia, cortical sensory deficit, alien limb phenomenon, postural instability, urinary incontinence, or behavioral change. Brain MRI at this time revealed nothing abnormal (Figure 1A). Reduction of dopamine transport binding was detected bilaterally in the anterior and posterior putamen (Figure 1B). ${ }^{123}$ I-metaiodobenzylguanidine (MIBG) scintigraphy uptake was within the normal range (Figure 1C). Brain ${ }^{123}$ I-IMP single-photon emission CT (SPECT) showed decreased perfusion in the bilateral occipital lobes (Figure 1D). The administration of levodopa did not improve the symptoms.

The proband's mother was a right-handed woman, who was clinically and genetically assessed before she died at age 76 years from ovarian cancer. She never learned to write or read in her life. She began having difficulty with her gait and fine motor skills of her right hand at age 63 years. She then gradually lost facial animation and experienced progressive cognitive decline. On examination at age 73 years, she exhibited marked lead-pipe rigidity of the neck and right limbs. She also exhibited delayed saccade initiation in the vertical plane, resting tremor in the right hand, the glabellar tap sign, and dysphagia. Brain MRI revealed moderate left superior parietal atrophy (Figure 1E). Marked reduction of dopamine transport binding was detected bilaterally in the anterior and posterior putamen (Figure 1F). MIBG scintigraphy uptake was within the normal range (Figure $1 G$ ). Brain SPECT showed decreased perfusion in the left temporal, parietal, and occipital lobes (Figure 1H). The administration of levodopa did not improve the symptoms.

The proband's youngest sister, a 45-year-old woman, also had difficulty in school. She completed high school with poor grades and then did some simple manual work like the proband. Although she did not complain of any symptoms, mild rigidity of the neck and right limbs was detected on examination. Repetitive hand, finger, and foot movements were slightly slow on the right.

We examined the proband and her youngest sister using the Japanese version of the Wechsler Adult Intelligence Scale, third edition (eTable 1, links.lww.com/NXG/A506). The proband showed very poor scores in all subtests. The cognitive impairment of the proband's youngest sister was most prominent in working memory.

All the family members were normocephalic, and there may not be any evident craniofacial anomalies in this family. However, the proband, her mother, and her youngest sister retain a strong family resemblance in facial appearance, characterized with relatively broad chin (eFigure, A-C, links.lww.com/NXG/ A506). On the other hand, the second daughter does not resemble the other 3 family members (eFigure, D).

\section{Molecular Findings}

We first performed whole-exome sequencing (WES) of genomic DNA from the proband but could not find any variations of the causative genes associated with parkinsonism or dementia (eTable 2, links.lww.com/NXG/A506). Moreover, no copy number variations in $S N C A, A P P$, or GBA were detected in the proband in semiquantitative PCR assays. WES was then performed using a quadruple diagnostic approach (the proband and her mother, aunt, and uncle) (Figure 2A). 

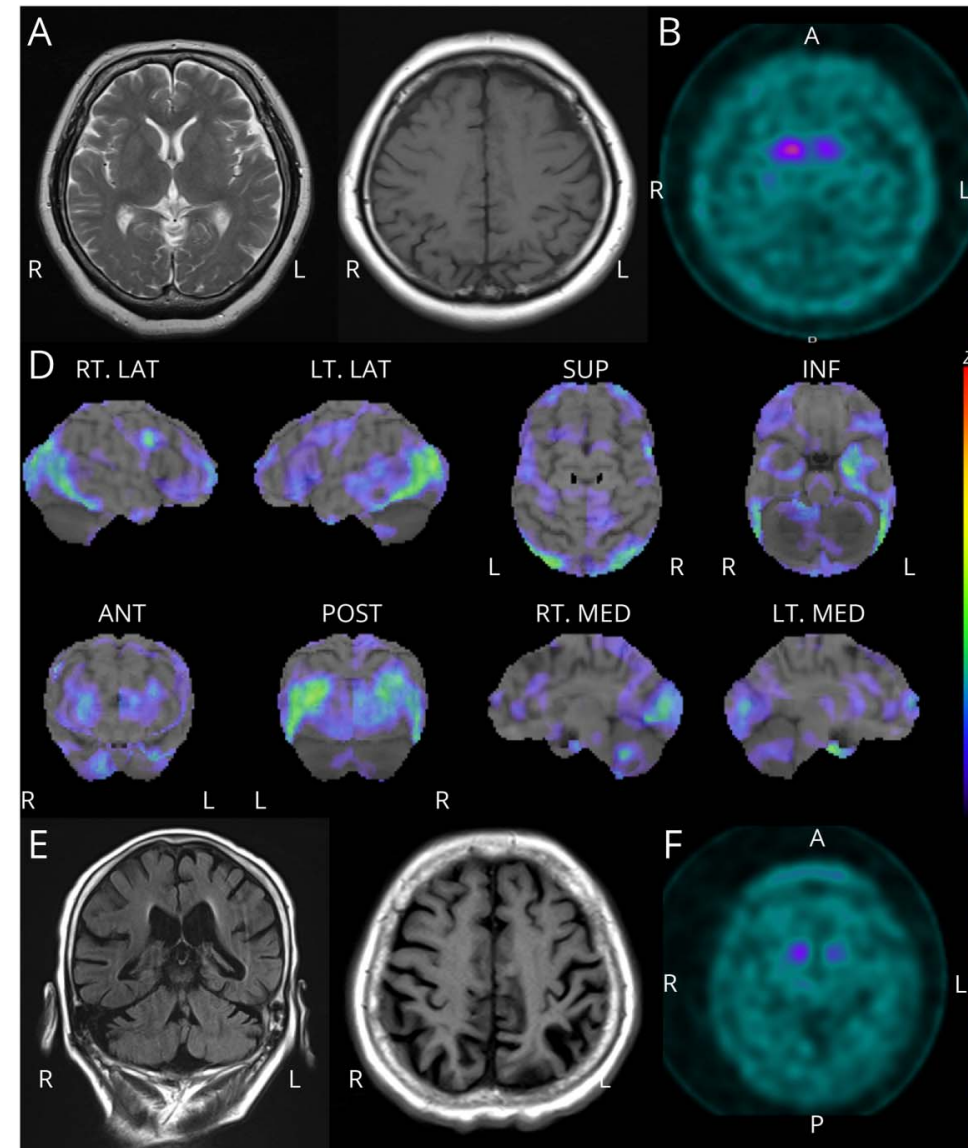

$\mathrm{R}$
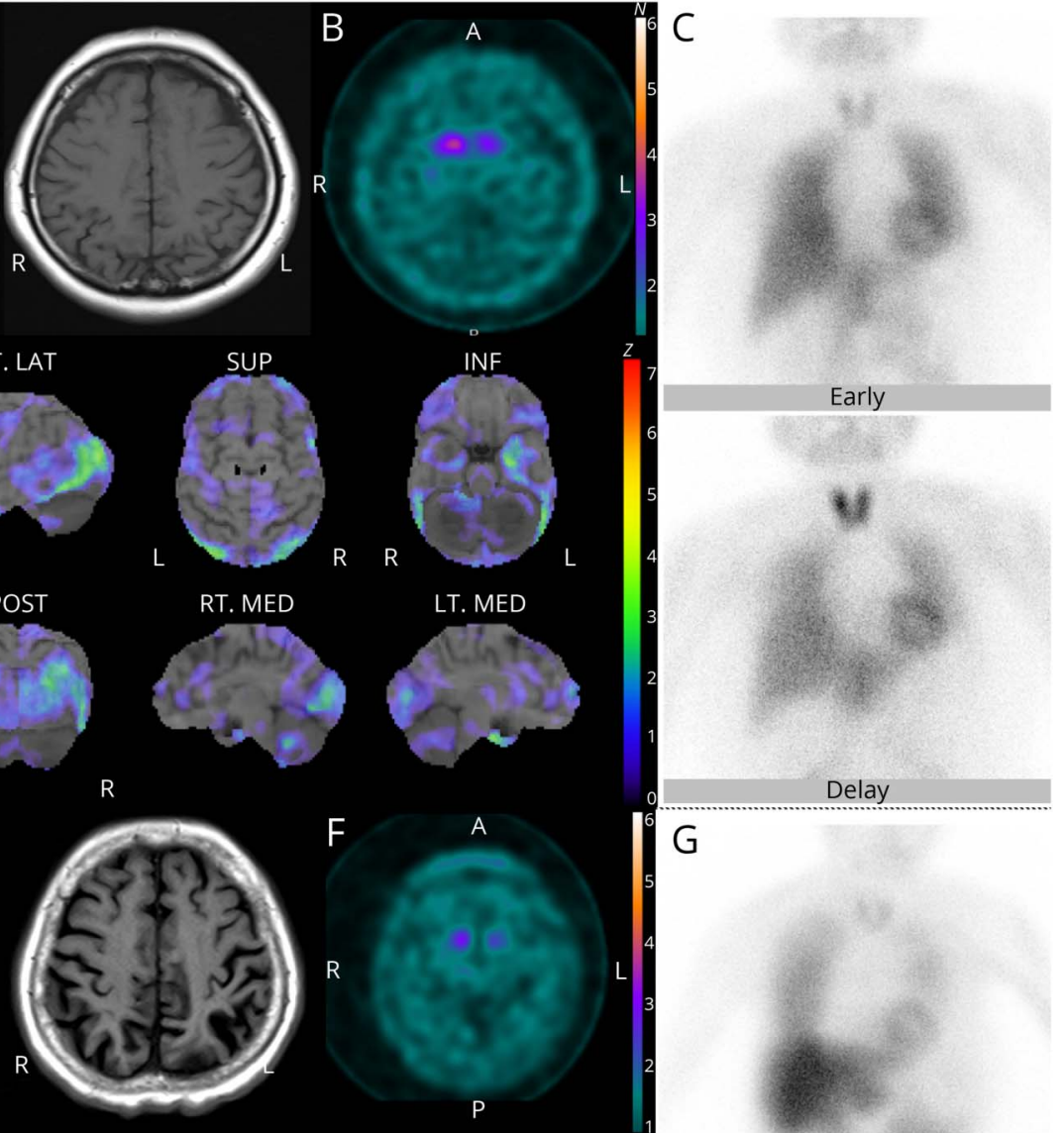

$\mathrm{F}$
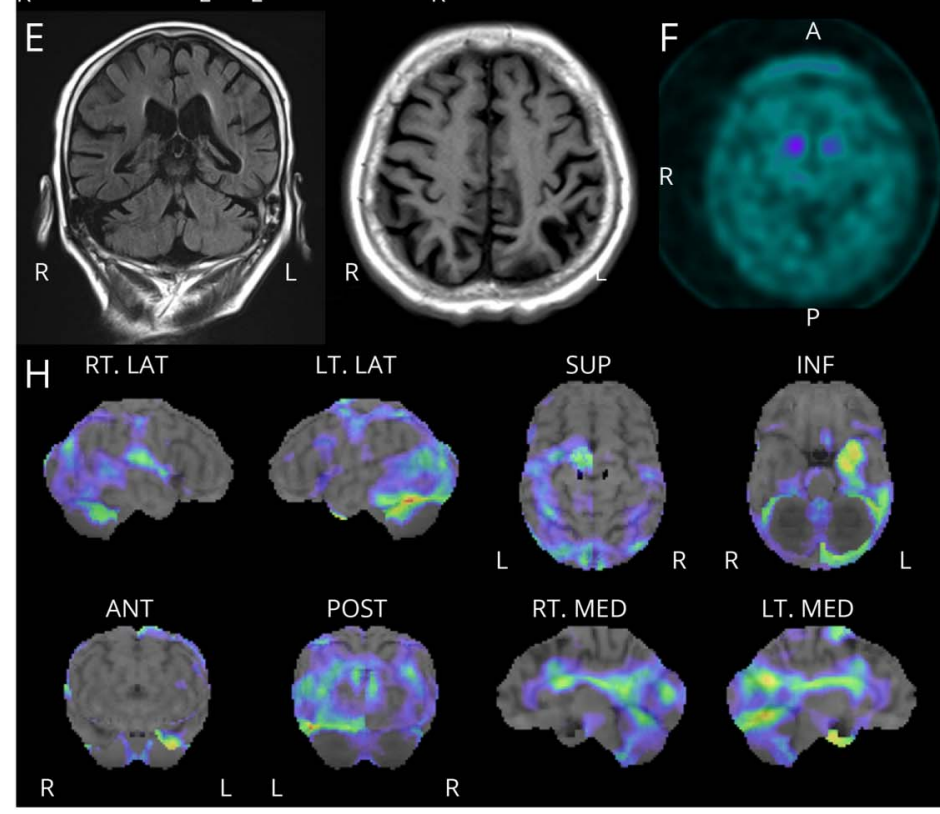

$\mathrm{R} \quad \mathrm{R}$
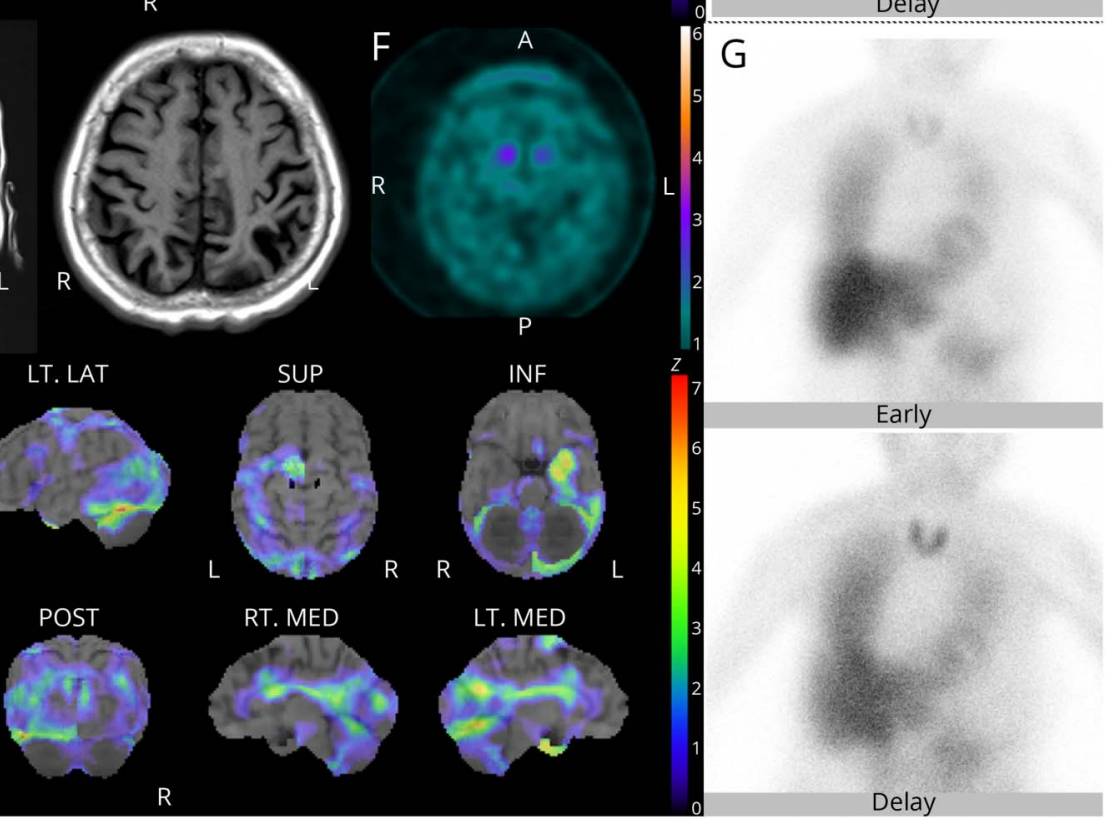

(A) Brain MRI of the proband revealed nothing abnormal. (B) Reduction of dopamine transport binding was detected bilaterally in the anterior and posterior putamen in the proband, with decreased specific binding ratios of 3.98 (right) and 3.16 (left). (C) MIBG scintigraphy uptake in the proband was within the normal range; the heart to mediastinum ratios in the early and delayed images were 3.12 and 3.30, respectively, and the washout rate was 24.3\%. (D) Brain SPECT of the proband showed decreased perfusion in the bilateral occipital lobes. (E) Brain MRI of the proband's mother revealed mild left superior parietal atrophy. (F) Marked reduction of dopamine transport binding was detected bilaterally in the anterior and posterior putamen in the proband's mother, with decreased specific binding ratios of 2.16 (right) and 1.20 (left). (G) MIBG scintigraphy uptake in the proband's mother was within the normal range; the heart to mediastinum ratios in the early and delayed images were 2.25 and 2.21, respectively, and the washout rate was $24.1 \%$. (H) Brain SPECT of the proband's mother showed decreased perfusion in the left temporal, parietal, and occipital lobes. MIBG $={ }^{123} \mathrm{l}$-metaiodobenzylguanidine; SPECT = single-photon emission CT.

The disease-causing variation frequency was set at less than $0.01 \%$, a dominant inheritance mode with full penetrance in both males and females being assumed. Through this analysis, we identified 16 variants that were in heterozygous states in the proband and her mother but negative in her aunt and uncle. By analyzing the 16 variants, we identified a novel missense variation (c.265T>C, p.Trp89Arg) in exon 1 of the SLC9A6 gene (NCBI NM_001042537.1). We also identified a missense variant $(\mathrm{c} .50 \overline{4} \mathrm{G}>\mathrm{T})$ in the CTTNBP2 gene that is associated with Noonan syndrome, but its possibility was later excluded by cosegregation studies. The other 14 variants were all irrelevant as to neurologic diseases or neuronal dysfunctions. On Sanger sequencing, we reconfirmed the c.265T $>C$ (p.Trp89Arg) variation in a heterozygous state in the proband (III-1) (Figure 2B), her mother (II-3) (Figure 2C), and her youngest sister (III-3) (Figure 2D). This variation was not detected in the proband's aunt (II-5), uncle (II-6), or younger sister (III2) without symptoms (Figure 2E). This Trp residue is 


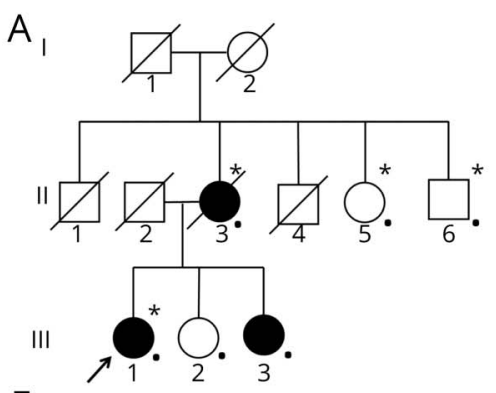

$\mathrm{F}$

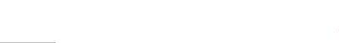

$\downarrow$

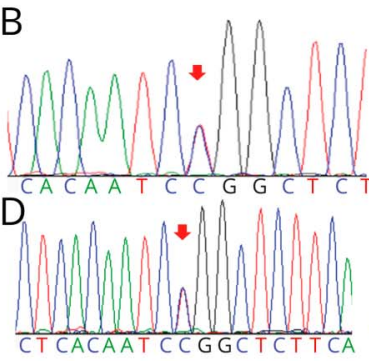

C

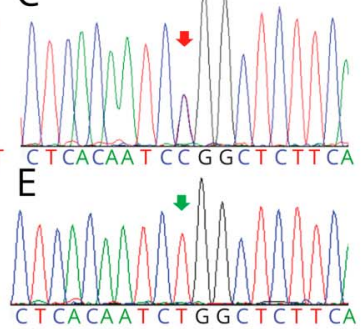

G

(A) Pedigree of the present family. The proband is indicated (arrow). Squares indicate males; circles, females; slashes, deceased individuals; shaded (black) symbols, individuals with symptoms of cognitive disability and atypical parkinsonism; unshaded symbols, individuals without any symptoms; individuals who underwent quad WES analysis are denoted by asterisks; and individuals assessed both clinically and genetically are denoted by dots. (B) Sanger sequencing revealed the c.265T>C variation in SLC9A6 in a heterozygous state in the proband. (C) Sanger sequencing revealed the c.265T>C variation in SLC9A6 in a heterozygous state in the proband's mother. (D) Sanger sequencing revealed the c.265T $>C$ variation in SLC9A6 in a heterozygous state in the proband's youngest sister. (E) The c.265T >C variation in SLC9A6 was not detected in the proband's aunt, uncle, or younger sister without symptoms. The green arrow indicates the c.265 nucleotide. (F) The Trp (W) residue is conserved in NHE6 orthologs from mammals to Caenorhabditis elegans. The $\operatorname{Trp}(\mathrm{W})$ residue is conserved in the 3 most closely related human NHE paralogs, NHE6, NHE7, and NHE9. The amino acid sequences used were as follows: NHE6 (human, Q92581); NHE7 (human, Q96T83); and NHE9 (human, Q8IVB4). (G) Bioinformatic analyses using Mutation Taster (mutationtaster. org), PolyPhen-2 (genetics.bwh.harvard. edu/pph2), PROVEAN, SIFT (provean. jcvi.org/genome submit 2.php), M-CAP (bejerano.stanford.edu/mcap/), and fathmmMKL (fathmm.biocompute.org. uk/fathmmMKL.htm) predicted that this variant was disease causing, probably damaging, deleterious, damaging, possibly pathogenic, and deleterious, respectively. This variation has a Combined Annotation-Dependent Depletion (CADD v1.6; cadd.gs.washington. edu/score) score of 28.7 and is not present in dbSNP (ncbi.nlm.nih.gov/snp/), HGMD (portal.biobase-international. com), GnomAD (gnomad.broadinstitute. org), HGVD (hgvd.genome.med.kyoto-u. ac.jp/), or ClinVar (ncbi.nlm.nih.gov/clinvar/). This variant is classified as likely pathogenic according to the ACMG standard (wintervar.wglab.org/). (H) The X-inactivation results in this family are presented before and after enzyme treatment. The proband and her mother, youngest sister, and noncarrier daughter had X-inactivation ratios of $74.8 \%, 68.6 \%$, $75.2 \%$, and $100 \%$, respectively. WES $=$ whole-exome sequencing.

conserved in NHE6 orthologs (Figure 2F). Bioinformatic prediction of this variant is shown in Figure 2G. This variant was not present in different population control data sets (Figure 2G).

An X-chromosome inactivation study was performed as previously reported. ${ }^{5}$ DNA samples from all female members of the family were digested with HpaII restriction enzyme.
$\mathrm{X}$-inactivation was considered as biased when it was greater than or equal to $85 \%$. The proband (III-1), her mother (II-3), and her youngest sister (III-3) had unbiased X-inactivation results, whereas complete skewing was observed in the noncarrier daughter (III-2) (Figure 2H).

To broaden our understanding of the molecular and cellular mechanisms underlying the variation (W89R), we examined 

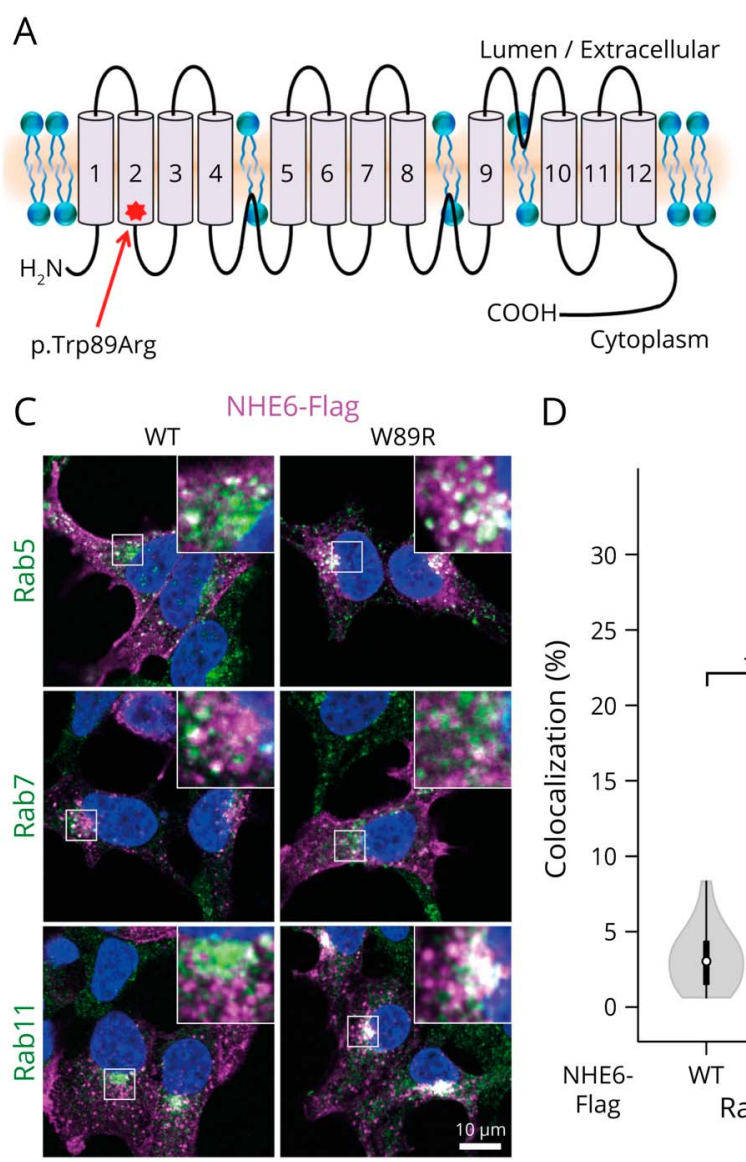

\section{B NHE6-Flag}
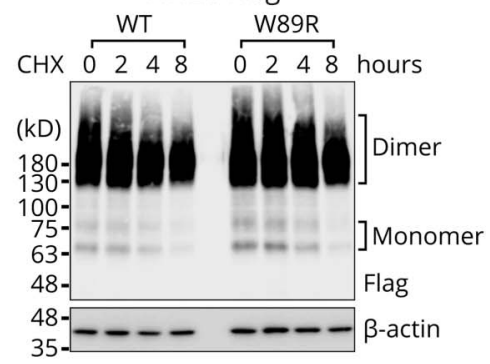

D

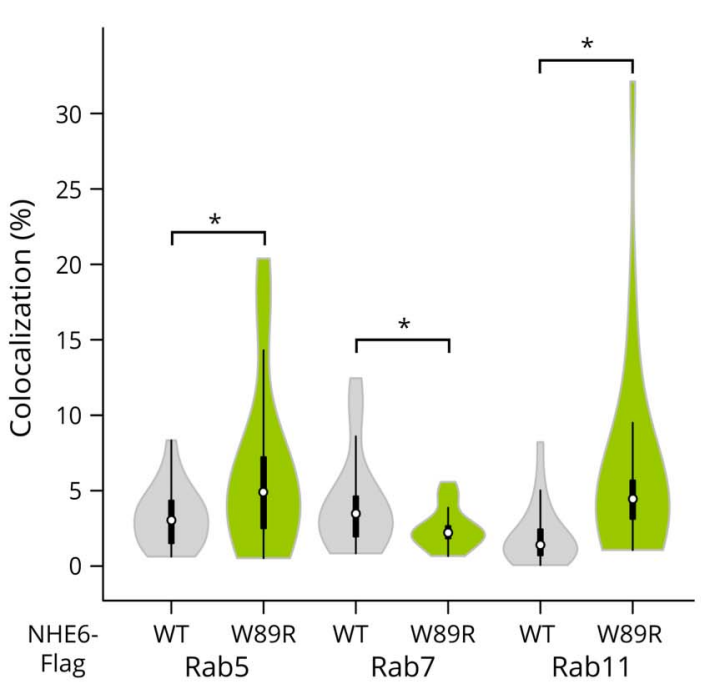

(A) A schematic diagram of the NHE6 protein with the predicted location of the variation in this family, based on NHE6 transcript NM_001042537. Transmembrane regions of NHE6 were predicted by SWISS-MODEL (swissmodel.expasy.org/) based on the crystal structure of the smaller bacterial Thermus thermophilus $\mathrm{Na}+/ \mathrm{H}+$ antiporter NapA (TtNapA). (B) To assess the protein stability of NHE6 variants, HEK293T cells were transiently transfected with FLAGtagged WT NHE6 or W89R NHE6 for 24 hours and then treated with $40 \mu \mathrm{g} / \mathrm{mL}$ cycloheximide $(\mathrm{CHX})$ for the indicated time points and lysed, and equal amounts of protein $(10 \mu \mathrm{g})$ were analyzed by Western blotting using a mouse monoclonal anti-DDDDK-tag antibody. Blots were reprobed with a mouse monoclonal anti- $\beta$-actin antibody as a control for protein loading, which was found to be constant over the treatment period. Blots are representative images from 3 independent experiments. (C) HEK293T cells transiently expressing FLAG-tagged WT NHE6 or W89R NHE6 were fixed, permeabilized, and labeled with anti-DDDDK (all), anti-Rab5 (upper lane), anti-Rab7 (middle lane), or antiRab11 (lower lane) antibodies. Randomly selected fields of images were obtained using a confocal microscope. The merged image shows the overlap of NHE6-Flag (Magenta) and early, late, or recycling endosomal markers Rab5, Rab7, and Rab11 (green), respectively. The boxed region is magnified for better representation (upper right corner). Bars, $10 \mu \mathrm{m}$. (D) The colocalization of WT or W89R NHE6 with endosome was quantified and plotted. WT = wild type. ${ }^{*} p<0.05$. the significance of the variation on the disease. The position of the variation is located at the second transmembrane region (Figure 3A), which is indicated in the planar transmembrane organization based on the prediction of TtNapA. ${ }^{6}$

In previous studies, some NHE6 variants showed varying degrees of impairment in posttranslational oligosaccharide maturation, protein stability, and membrane targeting. ${ }^{6}$ Therefore, we used HEK293T cells, a cell line derived from human embryonic kidney cells lacking detectable levels of endogenous NHE6 (data not shown), to evaluate the functional significance of the W89R NHE6 variant in our study. The protein half-life of NHE6 was examined by cycloheximide chase experiments. As shown in Figure 3B, levels of both the dimeric and monomeric forms of wild-type (WT) and W89R remained quite stable after cycloheximide treatment within the ensuing 8-hour period, without presenting obvious differences. These results suggest that there are no obvious differences between WT NHE6 and W89R variant regarding protein synthesis and degradation, posttranslational maturation, and dimerization.

Generally, NHE6 is an integral component of early and recycling endosomes and the cell surface. The impairment of vesicle traffic of NHE6 might interfere with endolysosomal pathways and potentially lead to neurodegenerative disease. ${ }^{7}$ Therefore, we examined whether the W89R variation could change the subcellular distribution of NHE6 protein. To visualize the subcellular distribution of the WT and W89R NHE6, dual-labeling fluorescence confocal microscopy was performed with Flag-tagged WT or W89R NHE6 and Rab5, Rab7, and Rab11 used as early, late, and recycling endosome markers, respectively (Figure 3C). The WT and W89R NHE6 distributed throughout the cell, with fluorescence signals in punctuate structures, overlapped with early, recycling, late endosomes, and the plasma membrane with appearance, suggesting that the tryptophan-to-arginine variation of NHE6 had no powerful impact on the overall distributions. However, in detail, W89R NHE6 protein presented a colocalization with the early endosome and the recycling endosome significantly higher than WT NHE6 (Figure 3D). The most predominant localization of W89R NHE6 was in the recycling endosome (Figure 3D). The observed localization pattern suggests that the W89R variation affects the membrane traffic processes of NHE6, which might potentially influence cellular homeostasis.

\section{Discussion}

Previous studies mentioned female carriers with SLC9A6 variations that developed atypical parkinsonism in late life (eTable 3, links.lww.com/NXG/A506). ${ }^{8-10}$ Our study revealed female 
carriers in a family with atypical parkinsonism symptoms notably worse on the right side, including bradykinesia, rigidity, and tremor. Both the proband and her mother presented with vertical gaze palsy, indicating a progressive supranuclear palsy-like picture. Neuroimaging studies revealed abnormalities mainly involving parietal regions and basal ganglia structures, which is most compatible with a diagnosis of corticobasal degeneration. However, the patients in this family do not meet the clinical diagnostic criteria of either corticobasal degeneration or progressive supranuclear palsy. ${ }^{11}$ Nevertheless, MIBG scintigraphy was normal in both patients, in keeping with a tau-related pathology.

The deposition of tau was shown in cortical and subcortical regions of the brains of patients with SLC9A6 variations. ${ }^{2}$ Moreover, it was found in postmortem brain tissues that decreased NHE6 expression was correlated with greater tau deposition. ${ }^{10}$ Our study further suggests that SLC9A6 variations might be associated with tau-related syndromes in females in late life.

NHE6 localizes on early/recycling endosomes and regulates endosomal $\mathrm{pH}$ by exporting $\mathrm{H}+$ out of the endosome lumen. Although we did not show the changes of endosomal $\mathrm{pH}$, our study suggests that WT NHE6 is transported from early endosomes to the plasma membrane and shuttles between the endosomes and plasma membrane via recycling endosomes. It is then transported to late endosomal compartments and ultimately degraded in the lysosomes. However, W89R NHE6 accumulates in the early and recycling endosomes and is only partly transported to late endosomes, indicating plausible impairment of the endocytic transport of W89R NHE6 destined for lysosomal degradation.

In conclusion, we present a family with a novel variation (c.265T>C, p.Trp89Arg) in the SLC9A6 gene, which segregated with intellectual disabilities and atypical parkinsonism. We characterized the stability and intracellular trafficking of W89R NHE6 protein and implicated its differential trafficking through the endocytic pathway, which may provide a possible link between this variation and a neurodegenerative phenotype.

\section{Acknowledgment}

The authors thank the members of the family for their help and participation in the study.

\section{Study Funding}

Grants-in-Aid from the Research Committee for Ataxic Disease (Y.T.), the Ministry of Health, Labor and Welfare, Japan, and JSPS KAKENHI Grant Number JP18K07495 (Y.T.) from the Ministry of Education, Culture, Sports, Science, and Technology, Japan.

\section{Disclosure}

The authors report no disclosures. Go to Neurology.org/NG for full disclosures.

\section{Publication History}

Received by Neurology: Genetics April 13, 2021. Accepted in final form November 15, 2021.

\begin{tabular}{|c|c|c|}
\hline Name & Location & Contribution \\
\hline $\begin{array}{l}\text { Haitian Nan, } \\
\text { MD }\end{array}$ & $\begin{array}{l}\text { University of } \\
\text { Yamanashi, Japan }\end{array}$ & $\begin{array}{l}\text { Literature search, genetic study, } \\
\text { interpretation of data, performing } \\
\text { the functional study, and draft } \\
\text { preparation }\end{array}$ \\
\hline $\begin{array}{l}\text { Yeon-Jeong } \\
\text { Kim, PhD }\end{array}$ & $\begin{array}{l}\text { University of } \\
\text { Yamanashi, Japan }\end{array}$ & $\begin{array}{l}\text { Major role in directing and } \\
\text { conducting the functional study, } \\
\text { developing functional research } \\
\text { strategies, interpreting functional } \\
\text { data, and critical revision }\end{array}$ \\
\hline $\begin{array}{l}\text { Mai Tsuchiya, } \\
\text { MD }\end{array}$ & $\begin{array}{l}\text { University of } \\
\text { Yamanashi, Japan }\end{array}$ & $\begin{array}{l}\text { Major role in acquisition and } \\
\text { analysis of data }\end{array}$ \\
\hline Aki Ishida, MD & $\begin{array}{l}\text { Yamanashi } \\
\text { University } \\
\text { Hospital, Japan }\end{array}$ & Acquisition of data \\
\hline $\begin{array}{l}\text { Hirotaka Haro, } \\
\text { MD, PhD }\end{array}$ & $\begin{array}{l}\text { University of } \\
\text { Yamanashi, Japan }\end{array}$ & Acquisition of data \\
\hline $\begin{array}{l}\text { Masaki } \\
\text { Hiraide, MD }\end{array}$ & $\begin{array}{l}\text { Kyonan Hospital, } \\
\text { Yamanashi, Japan }\end{array}$ & Acquisition of data \\
\hline $\begin{array}{l}\text { Toshihisa } \\
\text { Ohtsuka, MD, } \\
\text { PhD }\end{array}$ & $\begin{array}{l}\text { University of } \\
\text { Yamanashi, Japan }\end{array}$ & Critical revision of functional study \\
\hline $\begin{array}{l}\text { Yoshihisa } \\
\text { Takiyama, MD, } \\
\text { PhD }\end{array}$ & $\begin{array}{l}\text { University of } \\
\text { Yamanashi, Japan }\end{array}$ & $\begin{array}{l}\text { Conceptualization, supervision, } \\
\text { acquisition of data, critical revision, } \\
\text { and funding acquisition }\end{array}$ \\
\hline
\end{tabular}

\section{References}

1. Gilfillan GD, Selmer KK, Roxrud I, et al. SLC9A6 mutations cause X-linked mental retardation, microcephaly, epilepsy, and ataxia, a phenotype mimicking Angelman syndrome. Am J Hum Genet. 2008;82(4):1003-1010.

2. Garbern JY, Neumann M, Trojanowski JQ, et al. A mutation affecting the sodium/ proton exchanger, SLC9A6, causes mental retardation with tau deposition. Brain. 2010;133(pt 5):1391-1402.

3. Schroer RJ, Holden KR, Tarpey PS, et al. Natural history of Christianson syndrome. Am J Med Genet A. 2010;152A(11):2775-2783.

4. Pescosolido MF, Stein DM, Schmidt M, et al. Genetic and phenotypic diversity of NHE6 mutations in Christianson syndrome. Ann Neurol. 2014;76(4):581-593.

5. Lau AW, Brown CJ, Penaherrera M, Langlois S, Kalousek DK, Robinson WP. Skewed $\mathrm{X}$-chromosome inactivation is common in fetuses or newborns associated with confined placental mosaicism. Am J Hum Genet. 1997;61(6):1353-1361.

6. Ilie A, Gao AYL, Boucher A, et al. A potential gain-of-function variant of SLC9A6 leads to endosomal alkalinization and neuronal atrophy associated with Christianson syndrome. Neurobiol Dis. 2019;121:187-204.

7. Pescosolido MF, Ouyang Q Liu JS, Morrow EM. Loss of Christianson syndrome $\mathrm{Na}+/ \mathrm{H}+$ exchanger 6 (NHE6) causes abnormal endosome maturation and trafficking underlying lysosome dysfunction in neurons. J Neurosci. 2021; 41(44):9235-9256.

8. Sinajon P, Verbaan D, So J. The expanding phenotypic spectrum of female SLC9A6 mutation carriers: a case series and review of the literature. Hum Genet. 2016;135(8): 841-850.

9. Riess A, Rossier E, Kruger R, et al. Novel SLC9A6 mutations in two families with Christianson syndrome. Clin Genet. 2013;83(6):596-597.

10. Pescosolido MF, Kavanaugh BC, Pochet N, et al. Complex neurological phenotype in female carriers of NHE6 mutations. Mol Neuropsychiatry. 2019;5(2):98-108.

11. Alexander SK, Rittman T, Xuereb JH, Bak TH, Hodges JR, Rowe JB. Validation of the new consensus criteria for the diagnosis of corticobasal degeneration. J Neurol Neurosurg Psychiatry. 2014;85(8):925-929. 


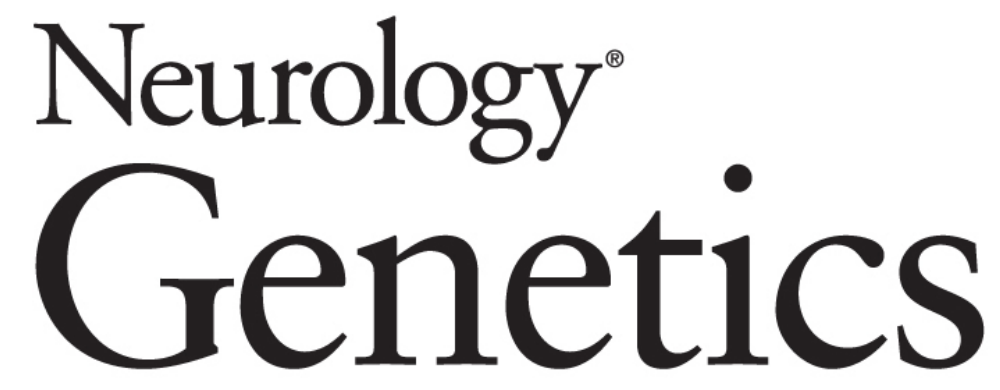

Novel SLC9A6 Variation in Female Carriers With Intellectual Disability and Atypical Parkinsonism

Haitian Nan, Yeon-Jeong Kim, Mai Tsuchiya, et al. Neurol Genet 2022;8;

DOI 10.1212/NXG.0000000000000651

This information is current as of January 18, 2022

Neurol Genet is an official journal of the American Academy of Neurology. Published since April 2015, it is an open-access, online-only, continuous publication journal. Copyright Copyright ( 2022 The Author(s). Published by Wolters Kluwer Health, Inc. on behalf of the American Academy of Neurology.. All rights reserved. Online ISSN: 2376-7839.

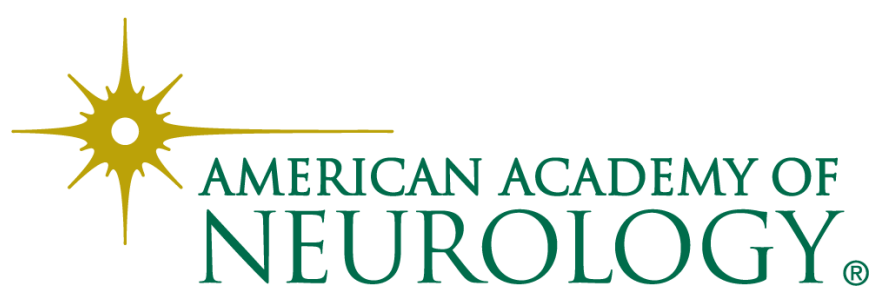




\section{Updated Information \& Services}

References

Subspecialty Collections

Permissions \& Licensing

Reprints including high resolution figures, can be found at:

http://ng.neurology.org/content/8/1/e651.full.html

This article cites 11 articles, 2 of which you can access for free at: http://ng.neurology.org/content/8/1/e651.full.html\#\#ref-list-1

This article, along with others on similar topics, appears in the following collection(s):

Corticobasal degeneration

http://ng.neurology.org//cgi/collection/corticobasal_degeneration

Intelligence

http://ng.neurology.org//cgi/collection/intelligence

Ion channel gene defects

http://ng.neurology.org//cgi/collection/ion_channel_gene_defects Parkinson's disease/Parkinsonism

http://ng.neurology.org//cgi/collection/parkinsons_disease_parkinsonis $\mathrm{m}$

Progressive supranuclear palsy

http://ng.neurology.org//cgi/collection/progressive_supranuclear_palsy

Information about reproducing this article in parts (figures,tables) or in its entirety can be found online at:

http://ng.neurology.org/misc/about.xhtml\#permissions

Information about ordering reprints can be found online:

http://ng.neurology.org/misc/addir.xhtml\#reprintsus

Neurol Genet is an official journal of the American Academy of Neurology. Published since April 2015, it is an open-access, online-only, continuous publication journal. Copyright Copyright $\odot 2022$ The Author(s). Published by Wolters Kluwer Health, Inc. on behalf of the American Academy of Neurology.. All rights reserved. Online ISSN: 2376-7839.

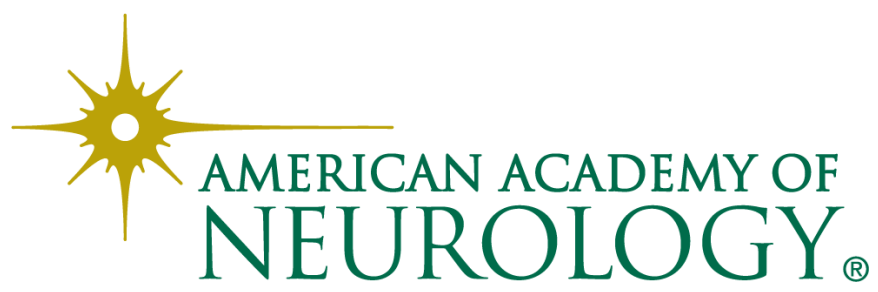

